\title{
EVALUATION OF THE CLINICAL OUTCOME OF SIX VERSUS FOUR STRANDS AUTOLOGOUS HAMSTRING GRAFT FOR AR- THROSCOPIC ANTERIOR CRUCIATE LIGAMENT RECONSTRUC- TION
}

\author{
Midhat M. Mahdi *, Ahmed K. Lafta \# \\ *M.B.Ch.B, C.A.B.S. Assistant Professor, Orthopedic Surgery, University of Basrah - College of Medicine - Department of \\ Surgery - Iraq, \# M.B.Ch.B. Basrah, Iraq.
}

\begin{abstract}
Anterior cruciate ligament $(\mathrm{ACL})$ injury is a common injury among sport men. Currently the arthroscopic reconstruction is the gold standard treatment in majority of cases. There are different ways to do the surgery, different approaches and different grafts. Each has its advantages and draw backs. The autologous four strands hamstring graft is a widely used graft. A new method of using six strands graft is now used to strengthen the graft.

This study is to compare the clinical outcomes of the patients underwent a six strand autologous hamstring graft ACL reconstruction and those done with four strands graft. It's retrospective and prospective comparative study carried out in Basrah Teaching Hospital. Started at January 2015. Twenty one patients with six strands graft included prospectively and 35 patients with four strands included retrospectively from previous study. All patients were subjected to the same procedure by the same surgeon. The patients are assessed preoperatively by stability tests and Tegner Lysholm score,then followed up after 6 months and after one year by the same tests and Tegner Lysholm score. Twenty one male patients with six strands graft have age ranging from 20 to 35 years (mean $26.1 \pm 3.9$ ). A thirty five patients with four strands were included, their age were $(24.6 \pm 2)$ years. In the six strands group $(71.6 \%)$ were sport men versus (82.8\%) in the four strands group. The six strands graft size ranged $8-11 \mathrm{~mm}$ with mean $(9.9 \pm 0.8) \mathrm{mm}$, while the four strands graft size ranged $7-9.5 \mathrm{~mm}$ with mean $(8.5 \mathrm{~mm})$. After one year the results was instability $(9.5 \%)$ of the six strands group versus $(25.8 \%)$ in the four strands group. The mean post- operative Tegner Lysholm score in six strands group was $(92.9 \pm 6)$ with excellent in $(85 \%)$ while it was excellent in $(22.8 \%)$ of the four strands group, although the mean Lysholm score not mentioned in the previous study.

In conclusions, the six strands autologous hamstring graft is an alternative method for ACL reconstruction particularly when the four strands graft cannot provide sufficient size.
\end{abstract}

Keywords: Anterior Cruciate Ligament (ACL) injury, hamstring graft, $\mathrm{ACL}$ reconstruction.

\section{Introduction}

A nterior cruciate ligament is the most common knee ligament that sustained injury, it has been estimated that 200000 are torn each year in USA \& 100000 ACL reconstruction done each year in USA ${ }^{1}$. Nowadays most of researches deal with the type of graft and technique used for reconstruction rather than the type of treatment (surgery or conservative).

The wide function of the ACL during various knee movement makes it the commonest ligament to be injured. This function include knee stabilization during cutting, turning, pivoting, acceleration and deceleration ${ }^{2,3}$. ACL injury is estimated to be two to eight times higher in females than males participating in the same sport ${ }^{4,5,6,7}$. In pediatric age group the ACL ligament may avulsed from its tibial attachment rather than torn $8,9,10$.
Type of patient management is greatly affected by patient factors with a preference toward early ACL reconstruction before giving way episodes occur 11. Young patient, pre injury hours of sporting and the amount of anterior laxity is a the main factors that correlate with the need for surgery ${ }^{1}$.

When surgery decision is made, the patient subjected to a serial protocols of preparing and rehabilitation include preoperative and postoperative measures that the patient should be aware about it preoperatively to make better results.

The result of the reconstruction surgery is affected by numerous factors whether preoperative, intraoperative or post - operative; such as chronicity of the injury, quadriceps muscle wasting, increase patient body mass index (BMI) ${ }^{12}, 13$, the graft size used ,associated injury, the presence of intra artic- 
ular lesion at the time of reconstruction and postoperative rehabilitation specially the early discharge from physical therapy before impairment are sufficiently resolved ${ }^{14}$. Graft size is of special important regarding the success of graft healing and the consequences of post-operative function and returns to sport and regarded as predictor of early revision after ACL reconstruction ${ }^{15}$.

In our center, previously we were used four strands hamstring autologous graft for ACL reconstruction and we could get satisfactory results . But sometimes we couldn`t get a sufficient graft diameter, so we increase the diameter of the graft by increasing the number of strands (folds), on the other hand a considerable number of our patients have poor compliance to physiotherapy that attributes to graft failure ${ }^{16}$, therefore stronger graft is required until complete healing.

This study is a complementary study to compare the clinical outcomes of the patient underwent a six strand autologous hamstring graft ACL reconstruction and those previously done with four strands. Hamstring graft uses is increasing last years because of little donor site morbidity than patellar tendon graft and its significant strength but it requires soft tissue to bone healing which is not efficient as bone to bone healing. Quadriceps tendon graft is strong enough to be used in ACL reconstruction especially in revision cases.

Arthroscopic ACL reconstruction: with advancement in arthroscopy and increase the understanding of graft selection the arthroscopic ACL reconstruction becomes the best option.

Graft selection: when decision of ACL made, graft selection is the next to decide. Auto graft is most commonly used but allograft and synthetics is also available. Auto graft has the advantage of less inflammatory reaction and no risk of disease transmission $.50 \%$ of autograft usually undergoes necrosis during healing process so a strong graft is needed initially. Many tissues around the knee joint can be used as a graft. Bone patellar tendon bone graft is widely used, it has the advantage of the presence of bone in both ends so it heals by direct bone to bone healing, it's main drawback is the morbidity at site of graft harvest specially during kneeling ${ }^{17}$.

Graft passage and fixation: the already prepared graft passed from tibial to femoral tunnel by aid of sutures and tension is applied from femoral side also cycling of the knee would help in tensioning the graft in tibial tunnel. Fixation methods used for femoral side are interference screws, endobuttons and transfixation pin, and for the tibia are interference screws, screws with spiked washers and staples. It's preferred to use a hybrid method of fixation such as double, triple or quadruple method 18

\section{Patients and methods}

This is a retrospective and prospective comparative study between four versus six strands autologous hamstring graft in arthroscopic ACL reconstruction, carried out in Al Basrah Teaching Hospital . Its complementary to a previous study done for patient with four strands ACL reconstruction. The first group is 35 patient with ACL rupture that underwent arthroscopic reconstruction with four strands autologous hamstring graft between October 2011 and January 2014 that retrospectively included from a previous study (mean group C 24.6 \pm 2 ). The second group underwent arthroscopic reconstruction with six strands autologous hamstring graft between January 2015 and October 2016 which include 32 patients; 11 of them were lost and we could follow 21 patients. It's a level III comparative study.

All the 21 patients with six strand graft were males with age 22 - 35 years $(26.14 \pm 3.6)$. Each patient was subjected to a questionnaire including full history and clinical examination and local knee joint examination especially stability tests Lachman's test, drawer test and pivot shift test. Thigh girth assessed bilaterally and a Tegner Lysholm score (Table 1) is calculated, it's a neumerical score of accepted responsiveness to be used for the knee functions after ACL injury. If the patient has severe pain and swelling that preclude a proper examination, then analgesia rest and knee splint was advised until pain and swelling decreased.

Each patient proved to have ACL rupture by the clinical examination sent routinely for plain X-ray A-P and lateral view to exclude avulsion fracture of tibial eminence or intraarticular fracture or to confirm Segond fracture. MRI is routine for each patient to confirm ACL injury and to check the state of articular cartilage, collateral ligament and associated meniscal injuries.

After the diagnosis is made the selected patient informed about the treatment modalities, in most 
Figure (1) Tegner Lysholm score

\begin{tabular}{|c|c|c|}
\hline \multirow{3}{*}{ 1. Limp (5 points) } & None & 5 \\
\hline & Slight or Periodic & 3 \\
\hline & Severe / Constant & 0 \\
\hline \multirow{3}{*}{ 2. Suppoert (5 points) } & None & 5 \\
\hline & Cane / crutch needed & 3 \\
\hline & Unable to bear weight & 0 \\
\hline \multirow{5}{*}{ 3. Locking (15 points) } & None & 15 \\
\hline & Catching & 10 \\
\hline & Occasional & 6 \\
\hline & Frequently & 2 \\
\hline & Currently Locked & 0 \\
\hline \multirow{6}{*}{ 4. Instability ( 25 points) } & Never gives way & 25 \\
\hline & Rarely with sports & 20 \\
\hline & Often with sports & 15 \\
\hline & Sometimes with ADL's & 10 \\
\hline & Often during ADL's & 5 \\
\hline & Every Step & 0 \\
\hline \multirow{6}{*}{ 5. Pain (25 points) } & None & 25 \\
\hline & Slight or Periodic & 20 \\
\hline & Severe / Constant & 15 \\
\hline & Marked walking $>2 \mathrm{~km}$ & 10 \\
\hline & Marked walking $<2 \mathrm{~km}$ & 5 \\
\hline & Constant & 0 \\
\hline \multirow{4}{*}{ 6. Swelling (10 points) } & None & 10 \\
\hline & After Sports & 3 \\
\hline & After daily activities & 2 \\
\hline & Constant & 0 \\
\hline \multirow{4}{*}{ 7. Stairs (10 points) } & No Problem & 10 \\
\hline & Slight Problem & 6 \\
\hline & One step at a time & 2 \\
\hline & Impossible & 0 \\
\hline \multirow{4}{*}{ 8. Suatting (5 points) } & No Problem & 5 \\
\hline & Slight Problem & 4 \\
\hline & Not beyond $90^{\circ}$ & 2 \\
\hline & Impossible & 0 \\
\hline
\end{tabular}

of the patients the option of surgery is discussed in details including the pre and post-operative physiotherapy, signing the inform consent of the operation, then the patient is scheduled for the surgery according to the inclusion criteria.
Patients inclusion and exclusion criteria: Patient included if he had proved ACL injury clinically and by MRI for more than one month, and he was active young skeletally mature patient (above 18 years) with good knee range of motion and injury 
within two years. The excluded patients are those with injury more than two years duration, degenerative knee changes, associated lateral collateral ligament (LCL) or medial collateral ligament (MCL) injury, sever quadriceps muscle wasting, younger age before epiphyseal closure, patients with ligamentous laxity, neuromuscular abnormality of the lower limbs and abnormal mentality.

Preoperative preparation: the patient was allowed to do preoperative physiotherapy in form of quadriceps muscle exercise to restore the quadriceps strength and full range of motion for the knee joint .The quadriceps girth should be equal to the contralateral side. Before surgery a preoperative formula is recorded, this formula contains patient identity, complaint, clinical examination and Lysholm knee score. We choose the Lysholm knee score because of simplicity and efficiency and because it used previously in patient with four stands graft that included in a previous study for comparison .

Operation: the patient admitted to the hospital one day before the surgery. Inform consent is signed. At the day of surgery the patient was re-examined on the operative table before and after the anesthesia. Shaving of the site of surgery by hair clipper then knee support is fixed to allow 90 degree knee flexion during the surgery, antibiotic dose given intravenous to the patient preoperatively, we usually use third generation cephalosporin (ceftriaxone 1 gram ). Pneumatic tourniquet of proper size was applied over the upper thigh, the pressure is about $100 \mathrm{~mm} \mathrm{Hg}$ over the systolic pressure. Local skin preparation with povidone iodine was done, then draping with sterile sheets.

Steps of the technique: anterolateral para patellar portal formal arthroscopy was carried out, screening of the knee joint cavity, all accessible knee regions must be examined including the intercondylar notch for ACL and PCL, the lateral compartment for menisci and articular cartilage, the medial compartment for the medial meniscus and the articular cartilage, suprapatellar pouch for patellofemoral joint medial and lateral recesses. After that anteriomedial portal is made for propping of the ACL and addressing any meniscal pathology (Figure 2).

Graft harvested through a $4 \mathrm{~cm}$ incision over the

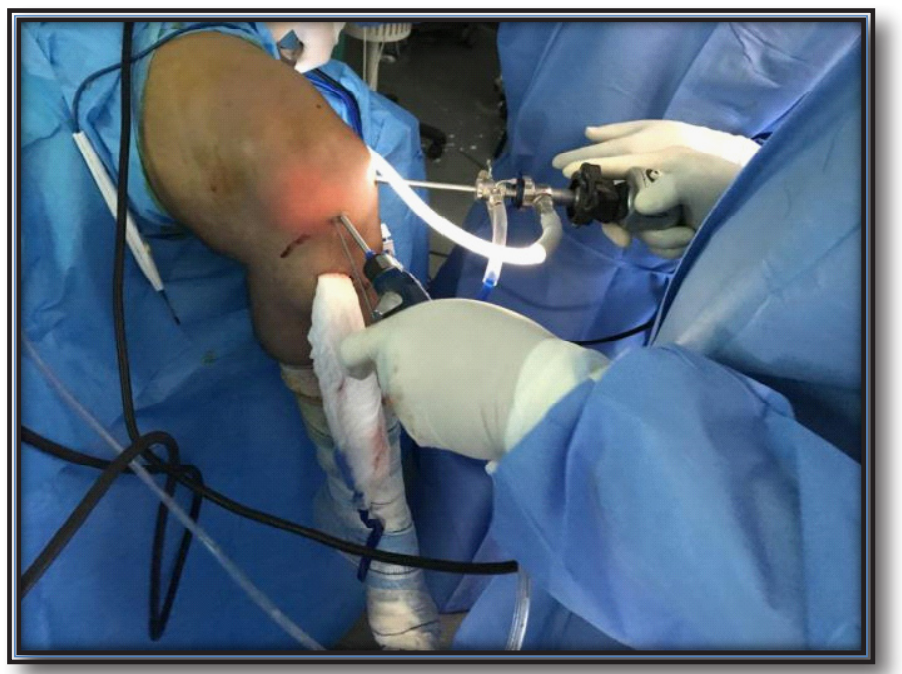

Figure (2) The anteromedial and anterolateral arthroscopic portals

insertion of pes anserinus about $4 \mathrm{~cm}$ distal to joint line and $2 \mathrm{~cm}$ medial to the tibial tuberosity. Identification of gracillis tendon and semitendinosus tendon first then a good release for the tendons is essential to prevent tendon disruption during harvesting. Stripping of the tendons done separately using open type tendon stripper.

Graft preparation: the graft is prepared on special trolley by removing any attached muscles. To create six strands graft first the two tendons su- tured one beside the other ( 2 strands), then folding the two tendons on one ends will produce four strands then folding the other end will produce a six strands graft. One of the ends would have a free suture end and the other would attach to the endobutton with loop, then the graft is pretentioned of about 20 newton for about 5-10 minutes. (Figure 3). Graft diameter was measured using a graft sizer.

During graft processing if there is any menis- 

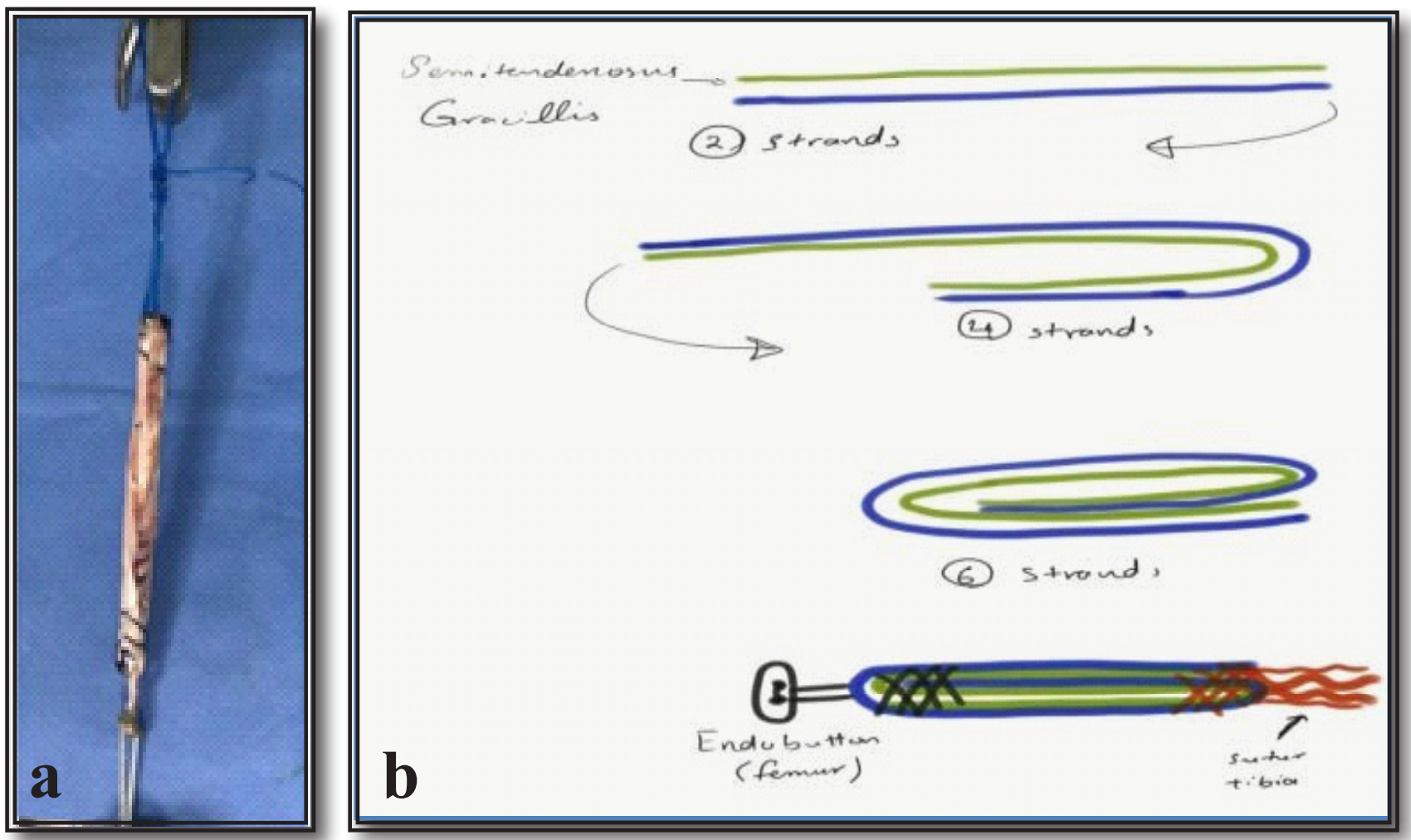

Figure (3) a,b 6-strands hamstring graft is sutured on both sides \& pretention is applied

cal pathology would be addressed and joint debridement and synovectomy were done if needed. Medial transportal femoral tunnel is drilled.The position is determined following the intercondylar ridge of lateral condyle most posteriorly leaving at least $2 \mathrm{~mm}$ thickness of posterior cortex and marked with bone awl. Notchplasty in six strands graft is always preferred to prevent graft impingement using shaver or radiofrequency ablation, appropriate aimer size is used according to graft size on tip posterior, Eye $\mathrm{K}$ wire is introduced through the aimer, $5 \mathrm{~mm}$ canulated drill is passed on the $\mathrm{K}$ wire for full tunnel perforation to pass the endobutton of the graft, the tunnel length measured by depth gauge then another drill according to graft size is passed to trim femoral tunnel at least 25-30 mm length. Tibial tunnel drilled using the wound of graft harvest. Tibial guide is placed at the ACL foot print or just posterior to the inner edge of lateral meniscus slightly toward the medial tibial spine. The guide angle is adjusted according to graft length, minimal graft length allowed is 9 $\mathrm{cm}$, as the graft at shorter and higher position is used. $\mathrm{K}$ wire is passed and staged drilling is done to keep centralization and reducing thermal effect starting with $6 \mathrm{~mm}$ then according to graft size.

The graft is advanced antegrade through both tunnels. The endobutton side passed first and sus- pended over the femoral cortex. The tibial side fixed with a titanium interference screw. Finally the graft position is checked for impingement.

The tourniquet was released, the wound was closed and knee was splinted in full extension with removable splint.

Post-operative rehabilitation: our recommended post-operative rehabilitation is depending mainly on home physiotherapy;

1. Day zero: ice bag was used, leg was elevated , antibiotic and analgesia were used. The patient discharged home (non-weight bearing) within 4872 hours.

2. 1 st week: the patient encouraged to do isometric quadriceps exercise and straight leg rising exercise. At the end of the 1st week the wound was inspected, the patient still kept in extension splint and non-weight bearing.

3. 2nd week: Continued quadriceps isometric exercise. By the end of the second week the stiches was removed and the splint was discontinued, starting knee flexion up to 90 degree and partial weight bearing (heel only touching the ground).

4. 4-6 weeks: performed quadriceps muscle exercise and hamstring sets (knee flexion against the couch).

5. After 6 weeks: used full weight bearing, performed quadriceps \& hamstring muscle exercise, 
encouraged full knee range of motion.

6. By the end of the sixth month: reevaluation by stability tests and recording the Lysholm knee score.

7. By the end of the nine month: the patient returned to normal pre injury physical activity.

8. 1 year: followed up by clinical examination and Lysholm knee score.

Data and Statistics: data were collected from the patients and recorded in a formula containing the identity, history, pre-operative examination, preoperative Lysholm score, intraoperative finding, six months post- operative examination, one year post- operative examination and Lysholm score.
The data analyzed using SPSS software version 20, chi square calculator and the Microsoft word and Microsoft end note for the references.

\section{Results}

A 32 patient with six strands autologous hamstring graft ACL reconstruction were included. Eleven of them were loss follow up, some of them were not willing to continue. All the patients were male, young with age ranging from 20 to 35 years, the mean age were $(26.1 \pm 3.9)$. A thirty five patients with four strands were included, their ages were between (21- 30 years), mean (24.6 2 ) as shown in Table (1).

Table (1) Age distribution

\begin{tabular}{||c|c|c||}
\hline & \multicolumn{2}{|c|}{ Number of patient } \\
\hline Age group (year) & Six strands group & Four strands group \\
\hline $20-30$ & $16(72.2 \%)$ & $27(77.2 \%)$ \\
\hline $30-40$ & $5(23.8 \%)$ & $8(22.8 \%)$ \\
\hline Total & $21(100 \%)$ & $35(100.0 \%)$ \\
\hline
\end{tabular}

For the six strand group 6 patients out of the 21 (28.4\%) were non sport men and injured by non sport mechanism and 15 of them $(71.6 \%)$ were sport men that registered in clubs and have a regular sport attendance (all are football player), their injury was during sporting .

While four strands group 29/35 patient (82.8\%) were sportsmen and have sport injury and 6 patient $(17.2 \%)$ with non sport injury as shown in Table (2).

Table (2) sport profession distribution

\begin{tabular}{||c|c|c||}
\hline \multirow{2}{*}{ Mechanism of injury } & \multicolumn{2}{|c|}{ Number of patient } \\
\cline { 2 - 3 } & Six strands group & Four strands group \\
\hline non sport injury & $16(28.4 \%)$ & $6(12.2 \%)$ \\
\hline sport injury & $15(71.6 \%)$ & $29(82.8 \%)$ \\
\hline Total & $21(100.0 \%)$ & $35(100 \%)$ \\
\hline
\end{tabular}

The six strands graft average size ranging between 8 -11 mm with mean $(9.9 \pm 0.8 \mathrm{~mm})$ while the four strands graft size range between (7-9.5) $\mathrm{mm}$ and the mean $8.5 \mathrm{~mm}$. The intra operative associated injury for both groups are shown in Table (3).

Giving way which is the cardinal sign of instability presented in $100 \%$ of both patients group pre operatively. Six months post-operative there are 2
/21 (9.5\%) of the six strands group that gave a history of giving way and this remain the same number after 1 year follow up Table (4).

In comparison in the four strands group there are 9/35 (25.8\%) patient gave history of giving way after 1 year follow up.

From these 2 patients with post-operative knee instability in the six strands group 1 patient $(4.8 \%)$ 
Table (3) Intra operative associated injury

\begin{tabular}{||c|c|c||}
\hline Associated injury & Six strand group & Four strands group \\
\hline Medial meniscus & $9(42.9 \%)$ & $10(28.5 \%)$ \\
\hline Lateral meniscus & $5(23.8 \%)$ & $0(0 \%)$ \\
\hline Articular cartilage & $2(9.5 \%)$ & $8(22.8 \%)$ \\
\hline
\end{tabular}

Table (4) post-operative giving way frequency

\begin{tabular}{||c|c|c||}
\hline & Six strand group & Four strands group \\
\hline No giving way & $19(90.5 \%)$ & $26(74.2 \%)$ \\
\hline giving way & $2(9.5 \%)$ & $9(25.8 \%)$ \\
\hline Total & $21(100.0 \%)$ & $35(100 \%)$ \\
\hline
\end{tabular}

The $p$-value is 0.139845 . The result is not significant at $p<0.05$

with( sometime instability at daily activity) and 1 the questionnaire of Lysholm score), both marked patient with frequent instability ( as mentioned in as ACL graft failure Table (5).

Table (5) post-operative instability in six strands group

\begin{tabular}{||c|c|c||}
\hline & Frequency & Percent\% \\
\hline Never & 19 & $90.4 \%$ \\
\hline Rare & 0 & 0 \\
\hline sometimes with daily activity & 1 & $4.8 \%$ \\
\hline Frequent with daily activity & 1 & $4.8 \%$ \\
\hline Total & 21 & $100.0 \%$ \\
\hline
\end{tabular}

In the four strand group 26 patients $(74.2 \%)$ had no instability, $7(20 \%)$ patients gave rare instability and $2(5.7 \%)$ give frequent instability with daily activity as shown in Table (6).

Table (6) post-operative instability in Four strands group

\begin{tabular}{|c|c|c||}
\hline & 6 months & 1 year \\
\hline Never & $25(71 \%)$ & $26(74.3 \%)$ \\
\hline Rare & $8(22.8 \%)$ & $7(20 \%)$ \\
\hline sometimes with daily activity & $0(0 \%)$ & $0(0 \%)$ \\
\hline Frequent with daily activity & $2(5.7 \%)$ & $2(5.7 \%)$ \\
\hline
\end{tabular}

In the six strands group the post operative Lachman's test was positive in 4/21 (19.1\%) and negative in 17 patients $(81 \%)$. Anterior drawer test is negative in $18(85.7 \%)$ patients and positive in 3
(14.3\%) patients. Lateral pivot shift test was negative in 20 patients $(95.2 \%)$ and positive in $1(4.8 \%)$ patient. The result compaired to four strands group in Table(7). 
Table (7) positive results of special tests

\begin{tabular}{||c|c|c|c|c|c|c||}
\hline \multirow{2}{*}{ Special test } & \multicolumn{2}{|c|}{ preoperative } & 6 month post operative & \multicolumn{2}{c|}{1 year post operative } \\
\cline { 2 - 7 } & Six strands & Four strands & Six strands & Four strands & Six strands & Four strands \\
\hline Lachman's test & $21(100 \% 0)$ & $35(100 \%)$ & $4(19 \%)$ & $2(5.7 \%)$ & $4(19 \%)$ & $2(5.7 \%)$ \\
\hline Anterior drawer test & $21(100 \% 0)$ & $25(71.4 \%)$ & $3(14.3)$ & $7(20 \%)$ & $3(14.3)$ & $5(14.2 \%)$ \\
\hline Pivot shift test & $12(57.1 \%)$ & $35(100 \%)$ & $1(4.8 \%)$ & $2(5.7 \%)$ & $1(4.8 \%)$ & $2(5.7 \%)$ \\
\hline
\end{tabular}

The $\mathrm{p}$-value is 0.48525 . The result is not significant at $\mathrm{p}<0.05$

Mean preoperative Lysholm knee score in the six strand group was $(68.8 \pm 17.9)$ increases to $(92.9 \pm 6)$ post operatively distributed as following fair (65$84)$ in 2 patients $(9.5 \%)$ and good (85-90) in 1 patient $(4.8 \%)$ and excellent in 18 patients $(85 \%)$.

Lysholm score in the four strand group post op- eratively was poor in $2 / 35$ patients $(5.7 \%)$, fair in 14 patients $(40 \%)$, good in 11 patients $(31.4 \%)$ and excellent in 8 patients $(22.8 \%)$ - Table (8), the mean not mentioned in the previous study.

The Lysholm score was higher in sportsmen in both groups as shown in Table (9).

Table (8) The results of lysholm score

\begin{tabular}{||c|c|c|c|c|c|c||}
\hline \multirow{2}{*}{ Lysholm score } & \multicolumn{2}{|c|}{ preoperative } & 6 month post operative & \multicolumn{2}{c||}{1 year post operative } \\
\cline { 2 - 7 } & Six strands & Four strands & Six strands & Four strands & Six strands & Four strands \\
\hline$<65$ poor & $12(57.1 \%)$ & $17(48.5 \%)$ & $0(0 \%)$ & $2(5.7 \%)$ & $0(0 \%)$ & $2(5.7 \%)$ \\
\hline $65-83$ fair & $6(28.6 \%)$ & $14(40 \%)$ & $2(9.5 \%)$ & $16(45.7 \%)$ & $2(9.5 \%)$ & $14(40 \%)$ \\
\hline $84-90$ good & $1(4.8 \%)$ & $4(11.4 \%)$ & $1(4.8 \%)$ & $10(28.5 \%)$ & $1(4.8 \%)$ & $11(31 \%)$ \\
\hline$>90$ excellent & $2(9.5 \%)$ & $0(0 \%)$ & $18(85 \%)$ & $7(20 \%)$ & $18(85 \%)$ & $8(22 \%)$ \\
\hline Total & $21(100 \%)$ & $35(100 \%)$ & $21(100 \%)$ & $35(100 \%)$ & $21(100 \%)$ & $35(100 \%)$ \\
\hline
\end{tabular}

The $p$-value is $<0.00001$. The result is significant at $p<0.05$

Table (9) Lysholm score in sport and non-sport patient

\begin{tabular}{||c|c|c||}
\hline & Six strands mean score & Four strands mean score \\
\hline Sportsmen & 93.1 & 91.7 \\
\hline Non sportsmen & 89 & 79.9 \\
\hline
\end{tabular}

The $p$-value is 0.648238 . The result is not significant at $p<0.05$

In our 21 patient with six strands graft we didn't face a noticeable complication except those with graft failure, no patient came with infection or deep venous thrombosis (DVT) or decrease knee range of motion .there is little complication happened in four strands group as shown in Table (10).

\section{Discussion}

Our study is designed to compare the results of four strands versus six strands hamstring graft. In the recent three years we change our technique to- ward six strands because we think that we need more graft strength for better results. The patient have nearly the same demographic criteria with those in four strand group and done under same circumstances .

Complications of ACL reconstruction surgery: ACL failure comes from different etiologies some of these complication are :-

1- Failure because of tunnel malposition it's the most common cause of failure which can be happened in coronal or sagittal plain. 
Table (10) Complications in four strands group

\begin{tabular}{|c|c|c|c||}
\hline Complication & Patient Number & Action & 6 months \\
\hline Infection & $2(5.7 \%)$ & conservative & Cured \\
\hline ACL failure & $2(5.7 \%)$ & Quadriceps exercise & Wait for revision \\
\hline Leg-foot parasthsia & $1(2.8 \%)$ & Different modality & Follow up \\
\hline
\end{tabular}

In coronal plain too vertical femoral tunnel (near12 O'clock) will not control the rotatory instability In sagittal plain too anterior femoral tunnel makes the knee tight in flexion and posterior placement of femoral tunnel makes the knee tight in extension For tibial tunnel; malposition in sagittal plain either anteriorly that lead to tightness in flexion and impingement in extension with the intercondylar notch or posterior tunnel placement will cause impingement with the posterior cruciate ligament.

2- Infection: septic arthritis presented with pain, swelling, redness and increased WBC count in the first two weeks treated with early arthroscopic irrigation and debridement and I.V. antibiotics.

3- Loss of motion because of arthrofibrosis. The most important factor for this is the preoperative range of motion. Arthrofibrosis is prevented by preoperative physiotherapy to gain full range of motion and by avoiding surgery during early inflammatory period after the injury and waiting until edema and erythema subside.

4- Infra patellar contracture syndrome.

5- Reflex sympathetic dystrophy

6- Hardware failure

7- Tunnel osteolysis

8- Local nerve irritation ( saphenous nerve)

9- Late arthritis usually related to meniscal injury 13.

Both six and four strands group has approximate age group, the six strand mean age was $(26.1 \pm 3.9)$ and the four strand was $(24.6 \pm 2)$. This age correlate with patient activity and sporting and the need to continue their activity. The age of the patients with ACL reconstruction vary in different studies but the commonest was close to our patient's age such as that done by Chen IL et.al. in which the mean patient age were 26 year.

About two third of the six strand group 15/21 (71.6\%) were sportsmen, and 6/21 (28.4\%) were non sportsmen. This ratio was higher in the four strands group. The sportsmen were $28 / 35$ patients
$(82.8 \%)$ and the non-sport were 6/35 (17.2\%) patients. This is happened randomly.

The medial meniscus injury was the commonest associated injury that found intraoperatively in the six strands group. It's found in 9/21 patients $(42.9 \%)$, while this is much less in the four strands group 10/35 (28.5\%). The meniscal injury in general either presented at time of the initial injury or it may be secondary to ACL tear after episodes of knee giving way, as a result the associated meniscal injury is related to the duration of the injury before ACL reconstruction done. The predominance of medial meniscal injury is supported by many studies such as the large study by Kilcoyne KG. et. al. ${ }^{18}$ in which the medial meniscus was the first associated injury (48.5\%) followed by lateral meniscus $(33.5 \%)$. Lateral meniscus injury is presented in 5/21 $(23.8 \%)$ in six strands group while none of the patient with four strands has lateral meniscus injury, this happened randomly and we think its non significant statistically. Matthias J Feucht ${ }^{19}$ shows there is $27 \%$ association between ACL tear and lateral meniscal tear at time of ACL reconstruction and this figure is vary greatly in different centers . Other study by Cristoph Dominic et. al. ${ }^{20}$ reveals wide range of lateral meniscal injury in association with ACL tear ranging from (17\%-51\%).

The articular cartilage damage is usually linked to the chronicity of the injury before the reconstruction. It presented in $2 / 21(9.5 \%)$ in the six strands group while in four strands group it presented in $8 / 35(22.8 \%)$. The later ratio is approximately same as the results that found by Noyes FR ${ }^{20}$ who found that the articular cartilage injured in $20 \%$ of patient at time of ACL reconstruction.

Post-operative giving way means graft failure that need to be revised; in this study there are $2 / 21(9.5 \%)$ in six strands group patients gave a post operative giving way during their daily activity. The four strands group gave a result of post operative giving way higher than those with six 
strands. The giving way in the four strands group found in 9/35 (25.7\%) patients; $p$ value $=0.139845$ which is statistically not significant. The instability was rare in $7 / 35(20 \%)$ patients and frequent in $2 / 35(5.7 \%)$ patients, although its not significant statistically, clinically we notice the overall instability is higher in the four strands group, this may be caused by the relative increase in the size of six strands graft that make it stronger and stiffer . Other possible cause that increase graft size would increase contact surface between the graft and the bone inside the femoral or tibial tunnel so it may improve the healing of the graft to bone.

In the six strands group the mean graft size was ranging $(8-11) \mathrm{mm}$. with mean $(9.9 \pm 0.8)$ while the four strands ranging (7-9.5) mm. with mean 8.5. The effect of the graft size is discussed in a study by Magnussen et. al. ${ }^{15}$, which contains 338 patient with ACL reconstruction he concluded that graft size $8 \mathrm{~mm}$ or less is associated with high revision rate which was as high as $13 \%$ in $7 \mathrm{~mm}$ graft. The importance of graft size is also confirmed by Mariscalco et. al. ${ }^{21}$, in which he concluded that smaller grafts (less than $8 \mathrm{~mm}$ ) is associated with poor knee function as compared with larger grafts and more revision rate especially in young patient. The increase in strands number mean increase in graft size that might contribute to better results. Rafael Calvo et.al ${ }^{22}$ had been used a five strands hamstring graft when the size of four strands is not enough, and found that there is no significant clinical differences between five strands and above 8 $\mathrm{mm}$ four strands graft.

Post operative stability test is greatly improved generally in both groups. The Lachman's test change from $100 \%$ positive preoperative to $4 / 21$ $(19 \%)$ post operative in six strands group and this figure is not changed in the 6 month and 1 year follow up. In four strands group the Lachman's test changed from $100 \%$ positive to $2 / 35(5.7 \%)$, despite that this higher rate of post operative positive Lachman test in the six strands group is not significant $(p$ value $=1.4462$ ) and its not associated with increase in post operative giving way, and this could be explained by the presence of some laxity in the knee joint but with firm end point that prevent giving way. Possible causes of the some laxity is inadequate graft pretensioning during the operation or graft elongation and deformation due to vigorous exercise post-operative particularly in non sportsmen patient who had poor muscle function postoperatively .

The anterior drawer test results post operatively didn't vary greatly between the two groups and was not significant as the pivot shift test.

Post operative Lysholm score improve significantly after the reconstruction in both groups ( $p$ value $=0.00001$ ) indicated that the knee function is improved in both groups after the surgery, but the difference between the six and the four strands group was not achieved statistical significant.

The Lysholm score was higher in sportsmen in both groups. The explanation for the better results in sport patient that the professional sport patients have better performance in physiotherapy, and they are more compliant to the regimen, also mostly they have already better quadriceps strength and they have more motivation to return to pre injury level of activity. We couldn't find a study supporting this results and the ACL injury already regarded as sport injury that make the majority of articles deal with sportsmen.

\section{Conclusions}

ACL reconstruction surgery can be done in different successful ways all are providing a good knee function post operatively.

Although it's statistically not significant, the results of six strands show superiority over the four strands group regarding the Lysholm score and the stability test, a good post-operative results are obtained in patient whom practicing sport regularly. Six strands graft is not technically difficult or demanding procedure without any added complications.

\section{Recommendations}

Six strands hamstring graft is a new method need to be further investigated by extensive longitudinal study and longer follow up.

When the graft size is small it's recommended to increase the size by increasing the number of strands, also providing specialized rehabilitation center under supervision of specialized well trained staff is vital for ACL surgery success.

In revision cases (failed) of the four strands probably six strands may be required for better results. 


\section{References}

1. campbell. CAMPBELL 'S OPERATIVE ORTHOPAEDICS. THIRTEENTH EDITION ed. . Frederick M. Azar M, James H. Beaty, MD, S.Terry Canale, MD editor. Philadelphia: ELSEVIER; 2017.

2. Siegel L, Vandenakker-Albanese C, Siegel D. Anterior cruciate ligament injuries: anatomy, physiology, biomechanics, and management. Clinical Journal of Sport Medicine. 2012;22(4):349-55.

3. MISSOURI UO. 3. https://shp.missouri.edu/vhct/case3505

/mech_injury.htm COLUMBIA: SCHOOL OF HEALTH PROFESSION; 2017 [

4. Harmon KG, Ireland ML. Gender differences in noncontact anterior cruciate ligament injuries. Clinics in sports medicine. 2000;19(2):287-302.

5. Hewett T, Myer G, Ford K. Decrease in Neuromuscular Control About the Knee With Maturation in Female Athletes. Journal of Orthopaedic \& Sports Physical. 2005;35(2):116.

6. Piasecki DP, Spindler KP, Warren TA, Andrish JT, Parker RD. Intraarticular injuries associated with anterior cruciate ligament tear: findings at ligament reconstruction in high school and recreational athletes. The American Journal of Sports Medicine. 2003;31(4):601-5.

7. Wojtys EM, Huston LJ, Schock HJ, Boylan JP, Ashton-Miller JA. Gender differences in muscular protection of the knee in torsion in size-matched athletes. JBJS. 2003;85(5):782-9.

8. Hall C. The hip. Therapeutic Exercise: Moving Toward Function Philadelphia: Lippincott, Williams and Wilkins. 1999:387436.

9. Kisner C, Colby LA. Therapeutic exercise. Foundations and techniques. 2002;4.

10. Magee D. Orthopaedic physical assessment WB Saunders. Philadelphia; 2002.

11. Jomha NM, Borton DC, Clingeleffer AJ, Pinczewski LA. Long Term Osteoarthritic Changes in Anterior Cruciate Ligament Reconstructed Knees. Clinical Orthopaedics and related research. 1999;358:188-93.

12. Kowalchuk DA, Harner CD, Fu FH, Irrgang JJ. Prediction of patient-reported outcome after single-bundle anterior cruciate ligament reconstruction. Arthroscopy: The Journal of Arthroscopic \& Related Surgery. 2009;25(5):457-63.

13. Lebel B, Hulet C, Galaud B, Burdin G, Locker B, Vielpeau C. Arthroscopic reconstruction of the anterior cruciate ligament using bone-patellar tendon- bone autograft: a minimum 10-year follow-up. The American journal of sports medicine. 2008;36(7):1275-82.

14. Chmielewski TL, Jones D, Day T, Tillman SM, Lentz TA, George SZ. The association of pain and fear of movement/reinjury with function during anterior cruciate ligament reconstruction rehabilitation. journal of orthopaedic \& sports physical therapy. 2008;38(12):746-53.

15. Magnussen RA, Lawrence JTR, West RL, Toth AP, Taylor DC, Garrett WE. Graft size and patient age are predictors of early revision after anterior cruciate ligament reconstruction with hamstring autograft. Arthroscopy: The Journal of Arthroscopic \& Related Surgery. 2012;28(4):526-31.

16. Ahmed Hazim Hammadi MMMMBCB, C.A.B.S. A Thesis Submitted to The Iraqi Board for Medical Specialization in Partial Fulfillment for The Fellowship of Iraqi Board of Medical Specialization in Fractures and Orthopedics Surgery.2014.

17. Schoderbek RJ, Treme GP, Miller MD. Bone-patella tendon-bone autograft anterior cruciate ligament reconstruction. Clinics in sports medicine. 2007;26(4):525-47.

18. Kilcoyne KG, Dickens JF, Haniuk E, Cameron KL, Owens BD. Epidemiology of meniscal injury associated with ACL tears in young athletes. Orthopedics. 2012;35(3):208-12.

19. Feucht MJ, Bigdon S, Bode G, Salzmann GM, Dovi-Akue D, Südkamp NP, et al. Associated tears of the lateral meniscus in anterior cruciate ligament injuries: risk factors for different tear patterns. Journal of orthopaedic surgery and research. $2015 ; 10(1): 34$.

20. Noyes FR, Bassett R, Grood E, Butler D. Arthroscopy in acute traumatic hemarthrosis of the knee. Incidence of anterior cruciate tears and other injuries. JBJS. 1980;62(5):687-95.

21. Mariscalco MW, Flanigan DC, Mitchell J, Pedroza AD, Jones MH, Andrish JT, et al. The influence of hamstring autograft size on patient- reported outcomes and risk of revision after anterior cruciate ligament reconstruction: a $\quad \mathrm{Multi}$ center Orthopaedic Outcomes Network (MOON) Cohort Study. Arthroscopy: The Journal of Arthroscopic \& Related Surgery. 2013;29(12):1948-53.

22. Calvo R, Figueroa D, Figueroa F, Vaisman A, Schmidt-Hebbel A, Morales N, et al. Five-strand hamstring autograft versus quadruple hamstring autograft with graft diameters 8.0 millimeters or more in anterior cruciate ligament reconstruction: Clinical outcomes with a minimum2-year follow-up. Arthroscopy: The Journal of Arthroscopic \& Related Surgery. 2017;33(5):100713 